\title{
Remineralization Potential of a Modified Eggshell- Titanium Composite-Scanning Electron Microscope Study
}

\author{
Stanley Chibuzor Onwubu ${ }^{1}$ Phumlane Selby Mdluli \\ ${ }^{1}$ Department of Dental Sciences, Durban University of Technology, \\ Durban, South Africa \\ 2Department of Chemistry, Durban University of Technology, \\ Durban, South Africa \\ ${ }^{3}$ University of KwaZulu-Natal, Westville, Durban, South Africa \\ ${ }^{4}$ Microscopy and Discipline of Dentistry, University of \\ KwaZulu-Natal. Westville. Durban. South Africa
}

\author{
Shenuka Singh ${ }^{3}$ Vishal Bharuth ${ }^{4}$
}

\begin{abstract}
Address for correspondence Stanley Chibuzor Onwubu, Department of Dental Sciences, Durban University of Technology, Durban, South Africa, (e-mail: 21445599@dut4life.ac.za).
\end{abstract}

Eur J Dent 2019;13:187-192

\begin{abstract}
Objectives This article reports the remineralization potential of a modified eggshelltitanium dioxide $\left(\mathrm{EB}-\mathrm{TiO}_{2}\right.$ ) composite in the management of $\mathrm{DH}$.

Materials and Methods The prepared composite was further characterized using different techniques such as Fourier-transform infrared spectroscopy (FTIR), X-ray diffraction (XRD), transmission electron microscopy (TEM), and field scanning electron microscopy (FSEM) to establish the modification. Forty freshly extracted bovine anterior teeth were used to evaluate the dentin tubule remineralization potential of $\mathrm{EB}^{-\mathrm{TiO}_{2}}$. Each tooth was sectioned mesiodistally to obtain dentin blocks. The dentin blocks were subsequently agitated in $4 \%$ wt. citric acid for 2 minutes to simulate sensitive tooth. Each dentin block was randomly assigned to five groups, namely Group 1: untreated, Group 2: EB alone, Group 3: EB- $\mathrm{TiO}_{2}$ treated, and Group 4: Colgate Sensitive, and Group 5: Sensodyne treated $(n=8)$ that were then subjected to remineralization protocol.

Results Both the XRD and FTIR images confirm the surface medication of EB-TiO, The TEM revealed a nonhomogeneous structure with an average particle size of $65 \mathrm{~nm}$.

Keywords

- dentin hypersensitivity

- eggshell

- remineralization

- titanium dioxide FSEM further was used to observe the remineralization capabilities of the samples. The FSEM image of the dentin specimens treated with $\mathrm{EB}^{-\mathrm{TiO}_{2}}$ shows complete remineralization of the dentin tubules, which remain intact postacidic exposure.

Conclusions This study confirmed that $\mathrm{EB}-\mathrm{TiO}_{2}$ composite effectively remineralizes dentin tubules. More so, the composite could be a cheaper and more efficient therapy material in the management of $\mathrm{DH}$.
\end{abstract}

\section{Introduction}

Dentin hypersensitivity (DH) is a relatively common complaint affecting more than $43 \%$ of adult's population worldwide. ${ }^{1}$ According to the Canadian advisory board on $\mathrm{DH},{ }^{2} \mathrm{DH}$ is characterized by distinctive short, sharp pain arising from exposed dentinal tubules, particularly in response to external stimuli that are typically thermal, evaporative, tactile, electrical, osmotic, or chemical changes that cannot be ascribed to any other form of dental defects or pathology. Concerning to oral care providers, DH negatively affects the quality of life for dental patients, as they become noncompliant with specific at home-care recommendations such as toothbrushing, thereby contributing to other oral care diseases. ${ }^{3}$

Of interest, to effectively control and manage $\mathrm{DH}$, several theories have been proposed in the last decades to explain 
the mechanism of DH. Currently, the hydrodynamic theory proposed by Brannstrom is widely regarded as the accepted theory. ${ }^{4}$ Hence, approaches to control the hydrodynamic mechanism have resulted in the development of two class of products, namely (1) occluding products or agents that reduce fluid flow within the dentin tubules and (2) agents or products that interfere with the transmission of nerve impulses. ${ }^{3,5}$ As the first-line therapy in the treatment of $\mathrm{DH}$, Yang et $\mathrm{al}^{6}$ advised using an occluding agent to physically block exposed dentin tubules.

Furthermore, occluding agents such as potassium oxalate, ${ }^{7}$ sodium fluoride, ${ }^{8}$ strontium salt, ${ }^{1}$ amorphous calcium phosphate containing casein phosphopeptide, ${ }^{9}$ and calcium glycerophosphate ${ }^{10}$ have been widely utilized in desensitizing paste for their dentin tubule occluding capabilities. However, the tubules occluded by some of these materials are reported to be superficial with limited infiltration depth. ${ }^{11}$ Consequently, patients experience relapse of pain as the occluded tubules are readily re-exposed in an acidic condition. ${ }^{12}$ Bearing these in mind, the development of a desirable biomaterial for DH becomes highly critical not only to efficiently occlude the exposed dentin tubules but also remain effective in an acidic environment.

Significantly, eggshells (EBs) have been investigated in recent years for their remineralization capabilities. ${ }^{13}$ For instance, Haghgoo et al ${ }^{14}$ reported that EB has a rich bioavailable calcium content that could favor the remineralizing of carious lesions. Cutler ${ }^{15}$ suggested that nano-sized titanium dioxide $\left(\mathrm{TiO}_{2}\right)$ and dental abrasive agents can be used together in occluding open dentinal tubules to effectively reduce $\mathrm{DH}$. Another study ${ }^{16}$ demonstrated that nano-sized $\mathrm{TiO}_{2}$ can improve the acid-resistant properties of calcium carbonates. Given the desirable properties of $\mathrm{TiO}_{2}$ and the remineraliza-

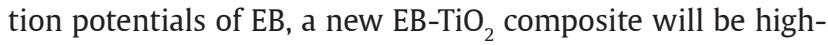
ly important for treating $\mathrm{DH}$. Therefore, however, there is limited evidence in the use of $\mathrm{EB}-\mathrm{TiO}_{2}$ for occluding dentin tubules. The present study aimed to evaluate the remineralization characteristics of $\mathrm{EB}^{-\mathrm{TiO}_{2}}$.

\section{Materials and Methods}

\section{Preparation of Eggshell-Titanium Dioxide Composite}

Modification of $\mathrm{EB}$ with $\mathrm{TiO}_{2}$ was achieved in two steps. In the first step, EBs were ball-milled by placing $30 \mathrm{~g}$ of the EB in a 500-mL stainless jar (inner diameter of $100 \mathrm{~mm}$ ), together with 10 stainless steel balls of $10-\mathrm{mm}$ diameter and dry-milled in a planetary ball mill (Retsch PM 100) at $400 \mathrm{rpm}$ for 20 minutes. The collected powder was sieved to a particle size of $\leq 25 \mu \mathrm{m}$ using a mechanical sieving shaker (Retsch AS 200, Germany). The EB powder and $\mathrm{TiO}_{2}$ mixing ratio were optimized following the procedure reported by giving author name ${ }^{17} ; 20 \mathrm{~g}$ of the fine EB powder obtained in Step 1 was modified by adding $5 \mathrm{~g}$ of anatase $\mathrm{TiO}_{2}(\leq 15 \mu \mathrm{m})$. The mixture was subsequently ballmilled for 100 minutes to obtain $\mathrm{EB}^{-\mathrm{TiO}_{2}}$ composite.

\section{Characterization of Eggshell-Titanium Dioxide} Fourier-Transform Infrared Spectroscopy Analysis

The infrared spectra were measured using a Perkin-Elmer Universal Attenuated Total Reflectance spectrometer to identify the functional group constituents of $\mathrm{EB}^{-\mathrm{TiO}_{2}}$.

\section{X-Ray Diffraction Analysis}

The X-ray diffraction (XRD) analysis was performed to observe the possible changes in crystallinity between the EB powder, $\mathrm{TiO}_{2}$, and $\mathrm{EB}-\mathrm{TiO}_{2}$. The XRD patterns were recorded using a diffractometer (PANalytical-Empyrean instrument; Co radiation: $1.54056 \mathrm{~A}^{\circ}$ ) and analyzed between 0 and $90^{\circ}(2$ theta). The voltage, current, and pass time used were $40 \mathrm{Kv}$, $40 \mathrm{~mA}$, and 1 second, respectively.

\section{Energy-Dispersive X-Ray Spectroscopy and Scanning Electron Microscope Analysis}

Energy-dispersive X-ray (EDX) spectroscopy was used in conjunction with a scanning electron microscope (SEM) (Field Emission, Carl Zeiss, Germany) operating at controlled atmospheric conditions at $20 \mathrm{kV}$ to examine the surface morphology and the elemental composition of the $\mathrm{EB}^{-\mathrm{TiO}_{2}}$. Before SEM observation, the surface was coated with a thin, electric conductive gold film to prevent the buildup of electrostatic charge.

\section{Transmission Electron Microscopic Analysis}

A transmission electron microscope (TEM) was used to observe the particle size, shape, and distribution of $\mathrm{TiO}_{2}$-EB. Very small quantities of $\mathrm{EB}^{-\mathrm{TiO}_{2}}$ were dispersed in $10-\mathrm{mL}$ ethanol and sonicated at $10 \mathrm{Kv}$ for 10 minutes. Subsequently, thin cross-sections of cryomicrotomed specimens were prepared using a Leica microtome (South Africa) and placed on carbon copper grids. The analysis was conducted using a TEM, Philips CM 120 model at $120 \mathrm{kV}$.

\section{Preparation of Dentin Tooth Specimens}

Forty freshly extracted bovine enamel anterior teeth were obtained from a slaughterhouse, South Africa. The collected teeth were subsequently cleaned and disinfected in $10 \%$ chloroxylenol solution. Dentin specimens measuring $5 \times 5 \times 1 \mathrm{~mm}$ were prepared by sectioning perpendicular to the long axis of the teeth below the enamel-dentinal junction using a low-speed diamond saw under water-cooling conditions. Thereafter, the prepared dentin specimens were wetly grounded with silicon carbide polishing papers (600-1000 grits) for 60 seconds. Before simulating the sensitive model, the specimens were mounted in a resin (Advanced Materials Technology Composite, South Africa). The dentin tubules were opened by soaking the specimens in $4 \%$ wt citric acid solution for 2 minutes to simulate sensitive tooth. Each dentin block was randomly assigned to five groups, namely Group 1: untreated, Group 2: EB alone, Group 3: $\mathrm{EB}^{-\mathrm{TiO}_{2}}$ treated, and Group 4: Colgate Sensitive and 
Sensodyne treated $(n=8)$ that were then subjected to remineralization protocol.

Evaluating In Situ the Remineralization and AcidResistant Characteristics of Eggshell-Titanium Dioxide In evaluating the remineralization potential of $\mathrm{EB}^{-\mathrm{TiO}_{2}}$, the prepared dentin tooth specimens were agitated in a beaker containing $1 \mathrm{~g}$ of the synthesized $\mathrm{EB}-\mathrm{TiO}_{2}$ and $40-\mathrm{mL}$ deionized water for 3 hours. The specimens were subsequently rinsed and blot-dried. The treated specimens were further exposed to $4 \%$ wt citric acid solution for 2 minutes. After exposure, the specimens were rinsed with deionized water and blot-dried.

\section{Energy-Dispersive X-Ray Spectroscopy and Scanning Electron Microscope Analysis}

EDX spectroscopy was used in conjunction with SEM (Field Emission, Carl Zeiss, Germany) operating at controlled atmospheric conditions at $20 \mathrm{kV}$ to examine the surface morphology and the elemental composition of the occluded dentin pre- and posttreatment and postacidic exposure. Before SEM observation, the surface was coated with a thin, electric conductive gold film to prevent the buildup of electrostatic charge.

\section{Results}

\section{Characterization}

The Fourier-transform infrared (FTIR) spectra of EB powder, $\mathrm{TiO}_{2}$, and EB-TiO ${ }_{2}$ is presented in - Fig. $\mathbf{1}$. The band aspect of the FTIR spectra shows the difference between the EB powder ( Although both EB powder ( - Fig. 1A) and $\mathrm{EB}^{-\mathrm{TiO}_{2}}$ ( - Fig. 1C) exhibit absorption peaks of carbonates at $1411 / \mathrm{cm}$, the broad stretching displayed for $\mathrm{EB}^{-\mathrm{TiO}_{2}}$ above below $1000 / \mathrm{cm}$ suggest the surface medication of calcium carbonate structure in $\mathrm{EB}$ powder with $\mathrm{TiO}_{2} \cdot{ }^{18}$

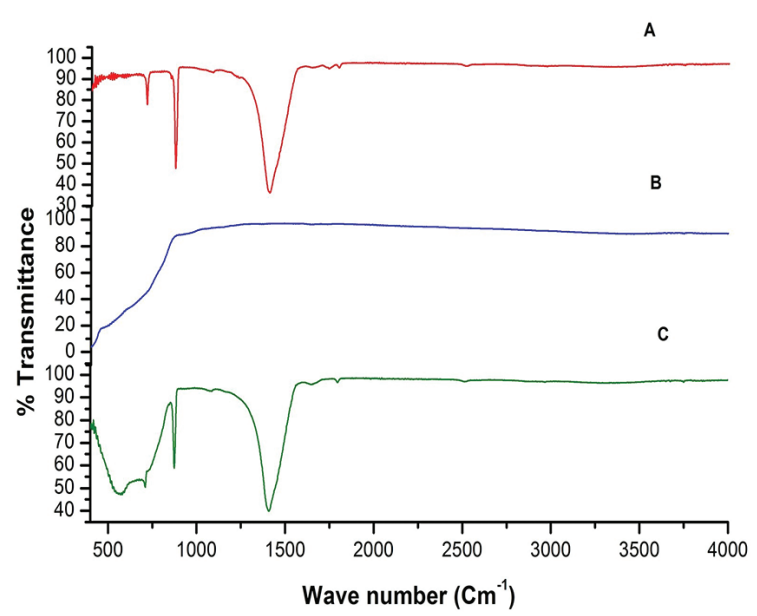

Fig. 1 Fourier-transform infrared spectra are showing (A) eggshellpowder. (B) Titanium dioxide. (C) Eggshell-titanium dioxide.

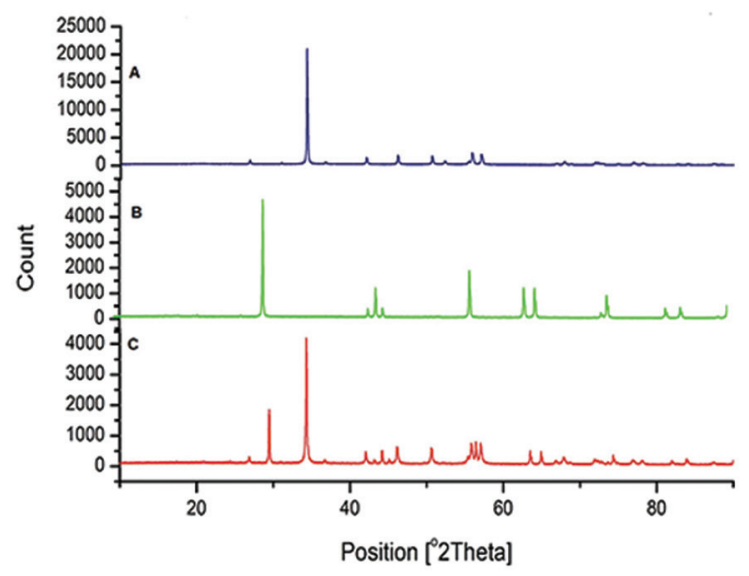

Fig. 2 X-ray diffraction pattern of (A) eggshell powder. (B) Titanium dioxide. (C) Eggshell-titanium dioxide.

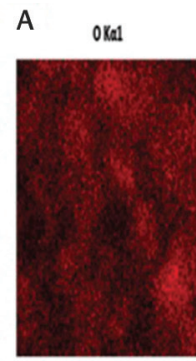

$\longdiv { 5 0 m }$

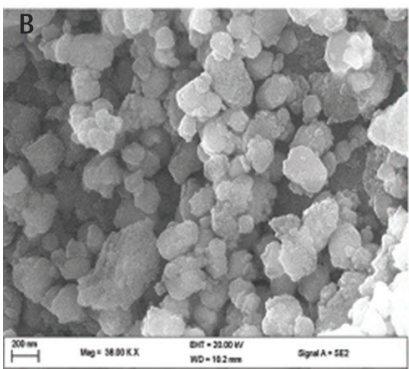

caklal

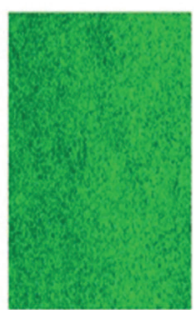

300

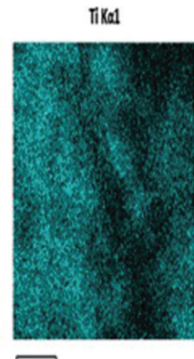

Silom
$\mathrm{CHall}_{2}$
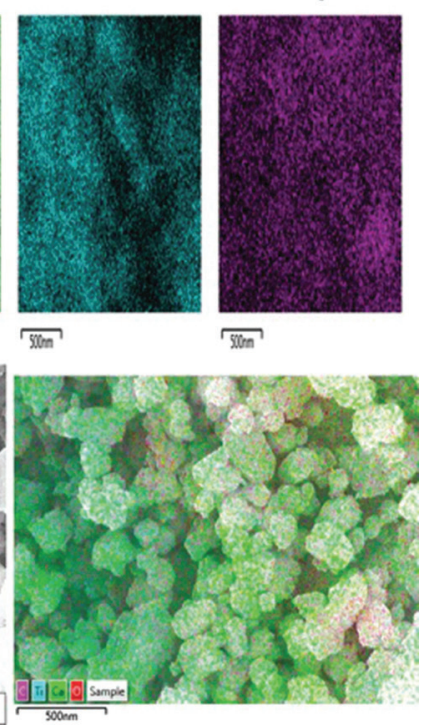

Fig. 3 Scanning electron microscope micrograph for (A) Eggshelltitanium dioxide. (B) Energy-dispersive X-ray mapping.

The XRD pattern of EB powder, $\mathrm{TiO}_{2}$, and $\mathrm{EB}-\mathrm{TiO}_{2}$ is presented in $\boldsymbol{- F i g}$. 2. For $\boldsymbol{- F i g}$. $\mathbf{3 A}$, the characteristic peak marked around $34.5^{\circ}(2 \theta)$ indicates the presence of thermodynamically stable calcite crystalline of the carbonate constituent in EB powder. ${ }^{18}$ In - Fig. 3B, the XRD pattern of pure $\mathrm{TiO}_{2}$ shows a characteristic diffraction peak with values lying at $2 \theta=29.5^{\circ}$ that corresponds to anatase phase and is confirmed with the International Centre for Diffraction Data (ICDD Ref: 98-009-6946). The $\mathrm{EB}^{-\mathrm{TiO}_{2}}$ diffraction peak shown in $\boldsymbol{- F i g}$. $3 \mathrm{C}$ revealed the presence of calcite and anatase crystalline structure. More importantly, and supporting the FTIR spectroscopy results, the XRD pattern of $\mathrm{EB}-\mathrm{TiO}_{2}$ exhibits a single-phase formation of the carbonate structure. This may likely be due to the balling time used. It is reported in the literature that calcium carbonate undergoes phase transformation on milling above 250 minutes. $^{19}$ 
The SEM images of the modified $\mathrm{EB}^{-} \mathrm{TiO}_{2}$ and the elemental mapping are illustrated in - Fig. 3 . As presented in -Fig. 3A, the SEM images show that approximately irregular and spherical particles coexisted. The irregular-shaped particles are indicative of EB powder, whereas the spherical particles typified the $\mathrm{TiO}_{2}$ particles. It can be observed that the pure $\mathrm{TiO}_{2}$ particles were scattered on the surface of the composite ( - Fig. 3A). More so, it can be seen that $\mathrm{TiO}_{2}$ sufficiently coated the EB powder particles and formed a compact layer of $\mathrm{TiO}_{2}$ firm. The said surface coating of $\mathrm{TiO}_{2}$ on the $\mathrm{EB}$ powder is further confirmed by the EDX mapping ( - Fig. 3B).

The EDX spectrum for the $\mathrm{EB}_{-} \mathrm{TiO}_{2}$ is shown in - Fig. 4. The high level of calcium, oxygen, and carbon could be attributed to the calcium carbonate constituent of EB powder. In addition, titanium is evidently present that confirm the surface modification of EB powder. This result correlates with the FTIR analysis in - Fig. 1.

The TEM image of $\mathrm{EB}^{-\mathrm{TiO}_{2}}$ is shown in - Fig. 5. Evidently, the TEM image revealed a nonhomogeneous structure of spherical-shaped particles and irregular particles with different sizes of distribution. Further to this, nanoparticles and some submicron particles were observed in the TEM images. The presence of submicron particles may be attributed to the commutation time used in achieving the modification of the composite.

\section{Remineralization}

The SEM micrograph of dentin tooth after abrading with silicon carbide for 60 seconds and subsequently exposed to $4 \%$ wt citric acid for 2 minutes is given in - Fig. 6 . The dentin tubules were hardly exposed after abrasion with silicon carbide for 60 seconds ( $\mathbf{- F i g . ~ 6 A )}$ ). In contrast, after exposure to $4 \%$ wt citric acid for 2 minutes, the dentin tubules were evident with increased diameter ( - Fig. 6B).

The SEM images of the dentin specimens treated with EB powder, EB-TiO 2 , Colgate, and Sensodyne not discussed in abstract or results above are seen in -Fig. 7. The images reveal occlusion differences between the $\mathrm{EB}^{-} \mathrm{TiO}_{2}$-treated specimens with the other test groups (EB powder, Colgate,

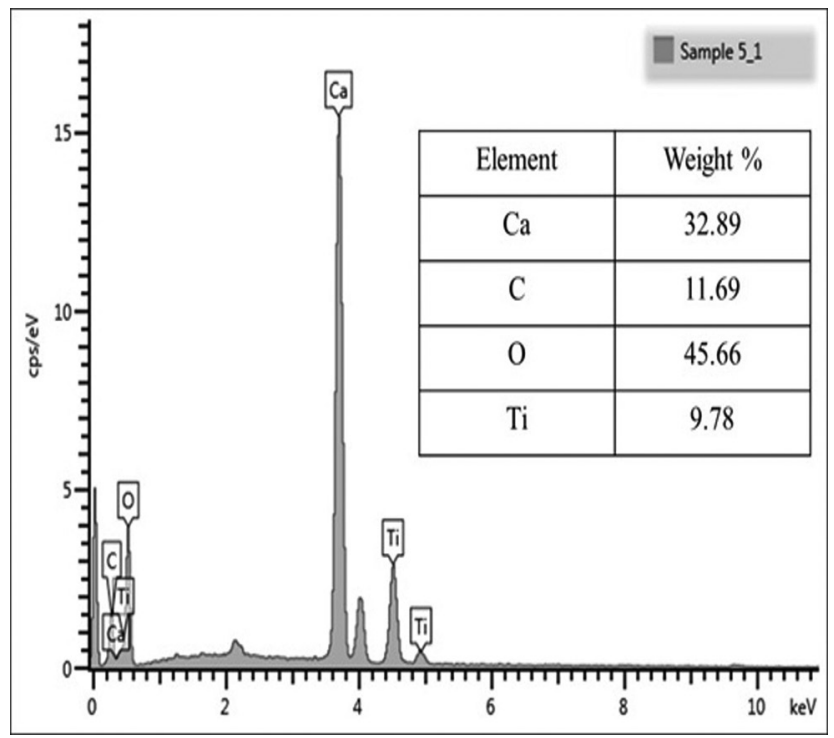

Fig. 4 Energy-dispersive X-ray spectrum of eggshell-titanium dioxide

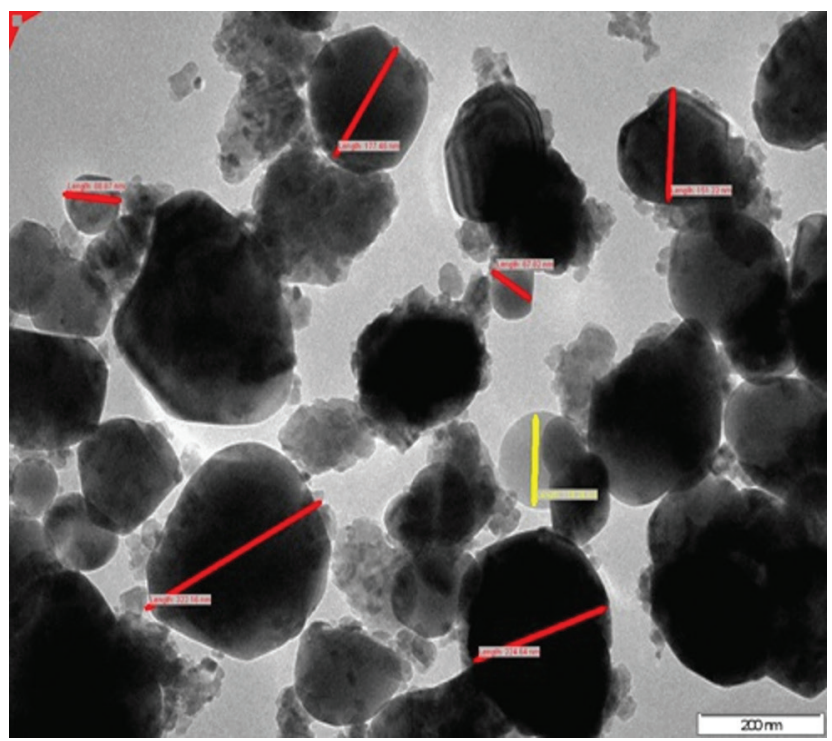

Fig. 5 Transmission electron microscope images eggshell-titanium dioxide.

and Sensodyne). The dentin specimen treated with $\mathrm{EB}-\mathrm{TiO}_{2}$ showed that nearly all the tubules are closed or remineralized with a compact surface ( $\boldsymbol{- \text { Fig. }}$ 7B). In contrast, and as shown in - Fig. 7A, Cand D, open tubules were visible on the dentin specimen treated with EB powder, Colgate, and Sensodyne, respectively.

Added to the above, the SEM micrograph of dentin specimen's treatment $\mathrm{EB}-\mathrm{TiO}_{2}$ and postexposure to citric acid is given in - Fig. 8. - Figure $\mathbf{8 A}$ visibly confirmed the remineralization of the dentinal tubules. Equally important, particles of $\mathrm{EB}^{-\mathrm{TiO}_{2}}$ deposits could be observed in the image at higher magnification, which suggests that the occluding or sealing of the tubules had depth and penetration. The EDX further confirmed Ti peaks for $\mathrm{TiO}_{2}$ ( - Fig. 8A1). The SEM image in - Fig. 8B revealed that the occluding bond remains intact after exposure to acid showing strong resistant to demineralization. This is also confirmed by the EDX spectrum ( - Fig. 8B1).

\section{Discussion}

The purpose of this study was to evaluate in situ the remineralization characteristics of a modified EB powder and $\mathrm{TiO}_{2}$ composite $\left(\mathrm{EB}-\mathrm{TiO}_{2}\right)$. The modification of $\mathrm{EB}-\mathrm{TiO}_{2}$ was achieved using a planetary ball-milling procedure. This technique is common mechanochemistry principle of producing fine powder in many different fields. ${ }^{20}$ The characterization results confirm that $\mathrm{EB}^{-\mathrm{TiO}_{2}}$ was successfully modified and the particle sizes obtained were in nano-dimension ( - Fig. $\mathbf{5}$ ). This finding is consistent with Tsai et $\mathrm{al}^{20}$ that planetary ball milling reduces particles to fine powder through the imposition of impact and frictional forces. More importantly, the presence of both carbonate structure and Ti-O-Ti stretching in the EB-TiO ${ }_{2}$ composite confirmed that the ball milling did not negatively impact on the carbonate composition of the $\mathrm{EB}$ powder ( - Fig. 1).

Although EB powder is predicted to be the future of tooth remineralization, ${ }^{13}$ the SEM images of the treated 

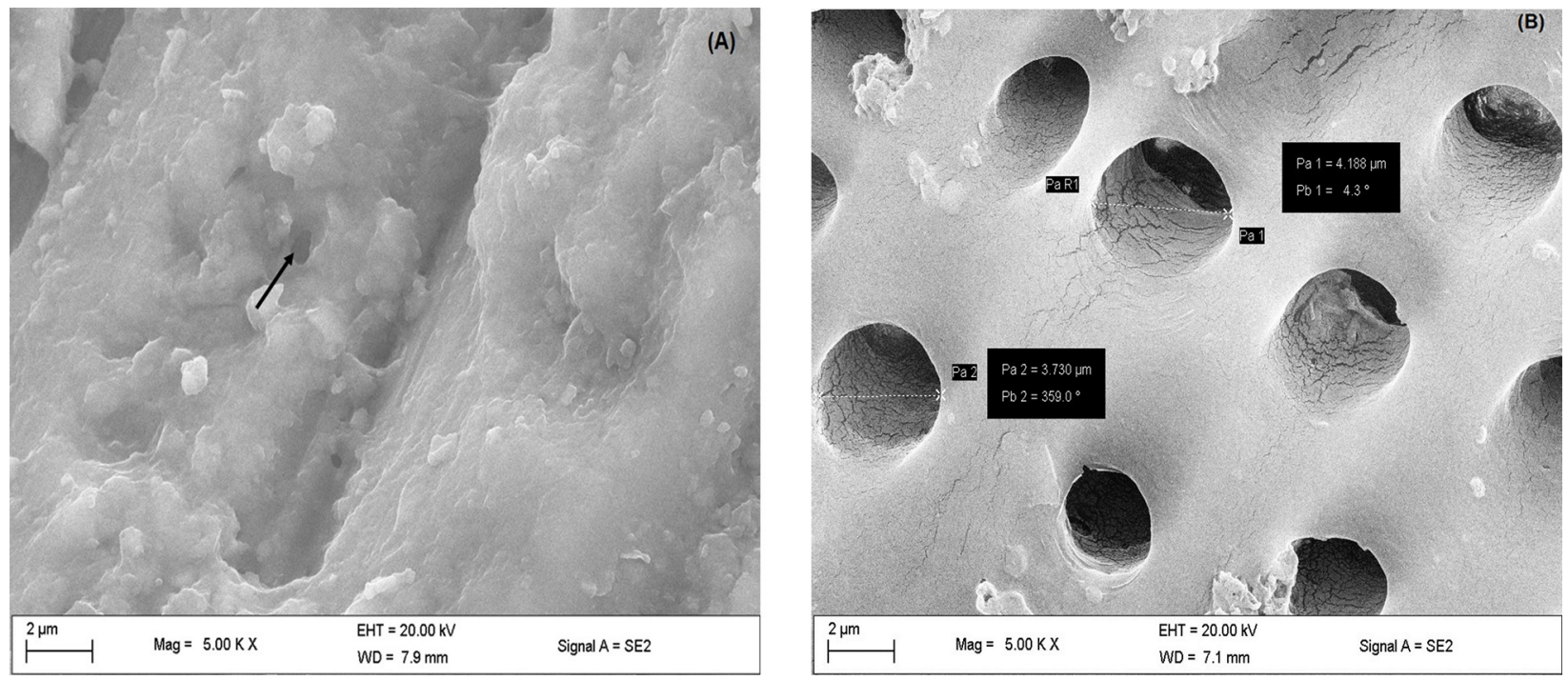

Fig. 6 Representative scanning electron microscope micrograph for (A) dentin surface wet ground with silicon carbide paper for 60 s. (B) Pretreatment of dentin surface exposed 4\% wt citric acid solution for 2 min (×5000). Arrows showing narrow dentin tubules.
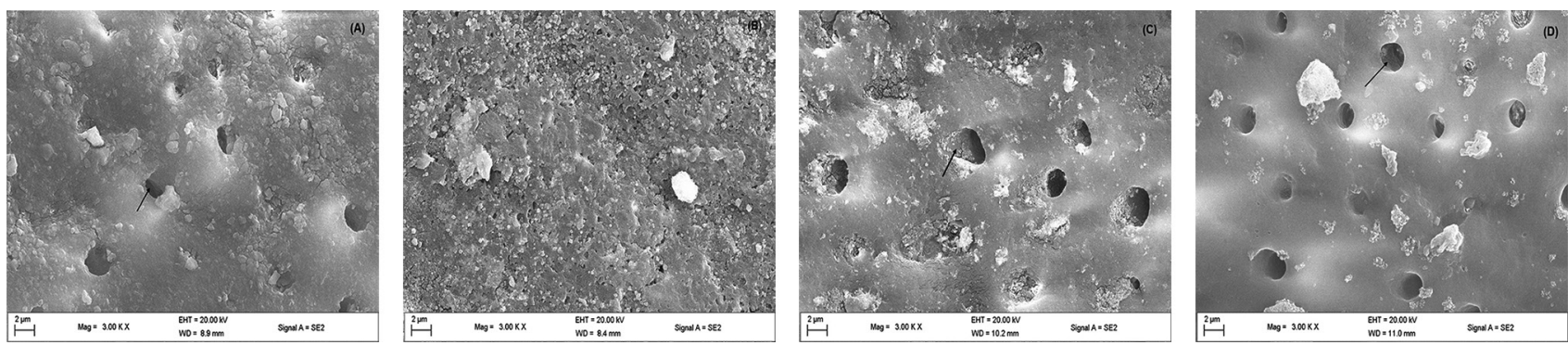

Fig. 7 Representative scanning electron microscope micrograph for dentin surface treated with (A) eggshell powder. (B) Eggshell-titanium dioxide. (C) Colgate. (D) Sensodyne (agitated for $3 \mathrm{~h}, \times 3000$ ). Arrows showing exposed tubules.
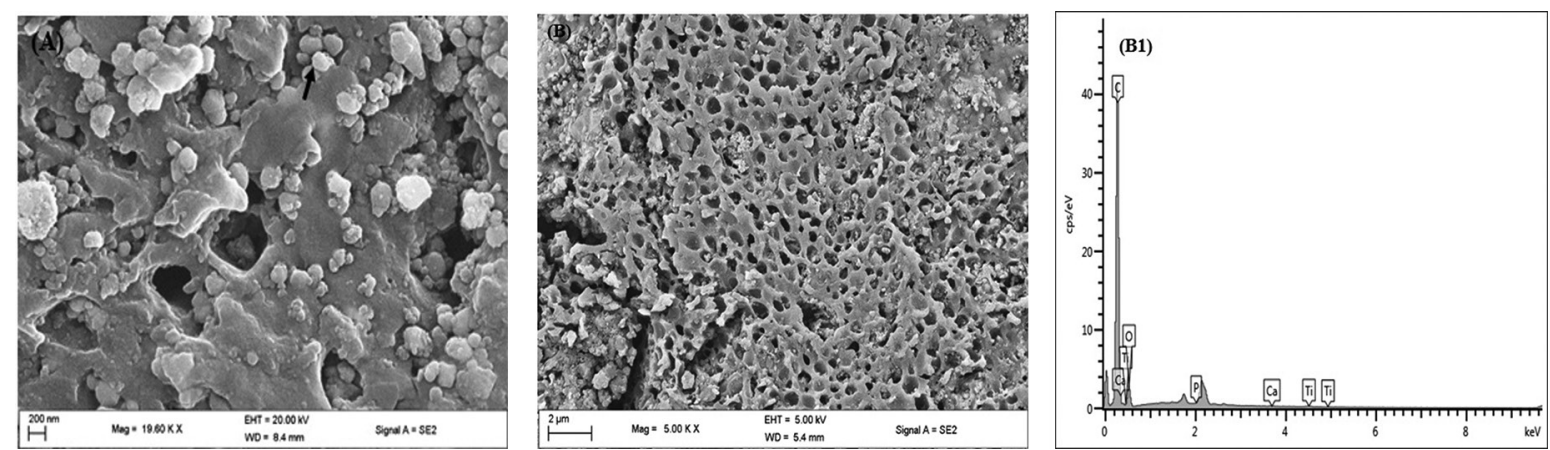

Fig. 8 Representative scanning electron microscope micrograph for (A) dentin surface after treatment with eggshell-titanium dioxide for $3 \mathrm{~h}$. (B) Dentin surface postexposure to 4 wt\% citric acid solution for $30 \mathrm{~min}(\mathrm{a}, \times 19000$; b × 5000). (a1) Energy-dispersive X-ray spectrum of the dentin surface treated with eggshell-titanium dioxide; energy-dispersive X-ray. (b1) spectrum of the dentin surface postexposure to 4 wt\% citric acid solution for 2 min. Arrows pointing to eggshell-titanium dioxide particles.

specimens suggest that modification of EB powder and $\mathrm{TiO}_{2}$ would be more effective in occluding dentin tubules ( - Fig. 7). Significantly, the dentin specimens treated with EB-TiO ${ }_{2}$ demonstrate outstanding seal as well as acid-resistant characteristics ( - Fig. 8). This is in agreement with Cutler ${ }^{15}$ suggestion that nano-sized $\mathrm{TiO}_{2}$ and dental abrasive agents can be used together in occluding open dentinal tubules to effectively reduce $\mathrm{DH}$. Moreover, the presence of $\mathrm{TiO}_{2}$ coating on the surface of $\mathrm{EB}-\mathrm{TiO}_{2}$ may have contributed to the occlusion remaining effective in an acidic environment ( $\boldsymbol{\sim}$ Fig. 8B). It can, therefore, be suggested that EB powder modified with $\mathrm{TiO}_{2}$ could potentially block open dentinal tubules while remaining intact in an acidic condition. This is in agreement with the report of Tao et $\mathrm{al}^{16}$ that $\mathrm{TiO}_{2}$ can improve the acid-resistant properties of calcium carbonates.

While several previous studies ${ }^{3,11,21}$ have reported on the remineralization and occluding potentials of Colgate and 
Sensodyne toothpastes, the findings from this study reveal that the occluding abilities of the tested toothpaste were inferior when compared with that observed for EB-TiO ( - Fig. 7). This could, however, be attributed to the brand of toothpaste tested. According to Schiff et al, ${ }^{22}$ desensitizing toothpastes such as Sensodyne and Colgate toothpastes are originally designed to deliver potassium ions that act as nerve-depolarizing agents in the treatment of DH. However, a new brand of Colgate, particularly calcium carbonate-arginine combination, has shown promising results in occluding dentin tubules. ${ }^{21}$ In light of the above findings, further studies are planned to examine both in vivo and clinical trial the effectiveness of $\mathrm{EB}-\mathrm{TiO}_{2}$ in the occlusion of open dentin tubules as well as its efficacy in reducing the threshold of pain associated with DH in comparison with other out of the counter toothpaste. These studies should help validate the suitability of $\mathrm{EB}-\mathrm{TIO}_{2}$ as a composite for the management of $\mathrm{DH}$.

\section{Conclusions}

In summary, both the XRD and FTIR results confirmed the successful modification of EB-TiO . The high-resolution TEM revealed a nonhomogeneous powder with an average particle size distribution of $65 \mathrm{~nm}$. Furthermore, the field electron scanning microscope (FESM) images suggest the $\mathrm{EB}^{-\mathrm{TiO}_{2}}$ composite could effectively remineralize and occlude dentinal tubules. It was also demonstrated that the remineralization capabilities of the composite were intact postacidic exposure. Importantly, EB-TiO 2 could provide a cheaper and efficient therapy material in the management of DH management. This could go a long way in reducing the global burden of waste in the environment.

\section{Funding}

The authors acknowledge the financial support from the National Research Foundation of South Africa (No. 104824).

\section{Conflict of Interest}

None declared.

\section{References}

1 Saeki K, Marshall GW, Gansky SA, Parkinson CR, Marshall SJ. Strontium effects on root dentin tubule occlusion and nanomechanical properties. Dent Mater 2016;32(2):240-251

2 Canadian Advisory Board on Dentin Hypersensitivity. Consensus-based recommendations for the diagnosis and management of dentin hypersensitivity. J Can Dent Assoc 2003;69(4):221-226

3 Schiff T, Delgado E, Zhang YP, Cummins D, DeVizio W, Mateo LR. Clinical evaluation of the efficacy of an in-office desensitizing paste containing $8 \%$ arginine and calcium carbonate in providing instant and lasting relief of dentin hypersensitivity. Am J Dent 2009; 22 Spec No A:8A-15A

4 Walters PA. Dentinal hypersensitivity: a review. J Contemp Dent Pract 2005;6(2):107-117
5 Panagakos F, Schiff T, Guignon A. Dentin hypersensitivity: effective treatment with an in-office desensitizing paste containing 8\% arginine and calcium carbonate. Am J Dent 200922 Spec No A:3A-7A

6 Yang ZY, Wang F, Lu K, Li YH, Zhou Z. Arginine-containing desensitizing toothpaste for the treatment of dentin hypersensitivity: a meta-analysis. Clin Cosmet Investig Dent 2016;8:1-14

7 Cunha-Cruz J, Stout JR, Heaton LJ, Wataha JC, Northwest PRECEDENT; Northwest PRECEDENT. Dentin hypersensitivity and oxalates: a systematic review. J Dent Res 2011;90(3):304-310

8 Pandit N, Gupta R, Bansal A. Comparative evaluation of two commercially available desensitizing agents for the treatment of dentinal hypersensitivity. Indian. J Dent Res 2012;23(6):778-783

9 Babu KG, Subramaniam P, Teleti S. Remineralization potential of varnish containing casein phosphopeptides-amorphous calcium phosphate with fluoride and varnish containing only fluoride: a comparative study. Saudi J Oral Sci 2018;5:35-40

10 Zalite V, Locs J. Characterization and preparation of calcium phosphate model toothpaste for tooth enamel remineralization. Key Eng Mater 2017;721:213-218

11 Arnold WH, Prange M, Naumova EA. Effectiveness of various toothpastes on dentine tubule occlusion. J Dent 2015;43(4):440-449

12 Yu J, Yang H, Li K, Lei J, Zhou L, Huang C. A novel application of nanohydroxyapatite/mesoporous silica biocomposite on treating dentin hypersensitivity: an in vitro study. J Dent 2016;50:21-29

13 Macri DV. Implementing a minimally invasive approach. Dimens Dent Hyg 2016;14:32-37

14 Haghgoo R, Mehran M, Ahmadvand M, Ahmadvand MJ. Remineralization effect of eggshell versus nano-hydroxyapatite on caries-like lesions in permanent teeth (in vitro). J Int Oral Health 2016;8:435-439

15 Cutler ET, Assignee. In: Patent U, ed. Prevention and Treatment of Oral Diseases. USA: Inventor Squigle, Inc.; 2014

16 Tao H, He Y, Zhao X. Preparation and characterization of calcium carbonate-titanium dioxide core-shell $\left(\mathrm{CaCO}_{3} @ \mathrm{TiO}_{2}\right)$ nanoparticles and application in the papermaking industry. Powder Technol 2015;283:308-314

17 Lin H, Dong YB, Jiang LY. Preparation of calcium carbonate particles coated with titanium dioxide. Int J Miner Metall Mater 2009;16:592-597

18 Onwubu SC, Vahed A, Singh S, Kanny KM. Physicochemical characterization of a dental eggshell powder abrasive material. J Appl Biomater Funct Mater 2017;15(4):e341-e346

19 Baláž M. Ball milling of eggshell waste as a green and sustainable approach: A review. Adv Colloid Interface Sci 2018;256:256-275

20 Tsai WT, Yang JW, Hsu HC, Lin CM, Lin KY, Chiu CH. Development and chracterization of mesporosity in eggshell ground by planetary ball milling. Microporous Mesoporous Mater 2008;111:299-386

21 Kleinberg I. SensiStat. A new saliva-based composition for simple and effective treatment of dentinal sensitivity pain. Dent Today 2002;21(12):42-47

22 Schiff T, Bonta Y, Proskin HM, DeVizio W, Petrone M, Volpe AR. Desensitizing efficacy of a new dentifrice containing 5.0\% potassium nitrate and $0.454 \%$ stannous fluoride. Am J Dent 2000;13(3):111-115 